\title{
High Pressure High Temperature Compaction of AA6061-AlNb Composite Powders
}

\author{
S. DĄBROWSKA AND D. OlESZAK* \\ Faculty of Materials Science and Engineering, Warsaw University of Technology, \\ Wołoska 141, 02-507 Warsaw, Poland
}

X-ray diffraction, scanning electron microscopy and hardness measurements were applied as experimental methods to investigate the structure and properties of the crystalline-amorphous Al-based composites prepared by mechanical alloying and subsequent high pressure high temperature compaction of the powders. It was possible to obtain bulk, fully dense crystalline-amorphous composites and the applied compaction technique allowed preservation of amorphous structure in the composite. Addition of amorphous $\mathrm{Al}_{60} \mathrm{Nb}_{40}$ phase to AA6061 alloy resulted in significant increase of hardness of the composite $(120 \mathrm{HV})$, comparing to pure Al alloy compacted at the same conditions $(75 \mathrm{HV})$.

DOI: 10.12693 /APhysPolA.126.928

PACS: 61.43.Dq, 81.20.Ev, 61.05.cp, 68.37.Hk

\section{Introduction}

There are many types of composite materials widely applied in various fields of technique, including metal, ceramic and polymer-based materials. Especially interesting from the application point of view is the group of Al-based metal matrix composites (MMC). There is a variety of fabrication methods and techniques of this kind of materials, including traditional powder metallurgy route. As reinforcement usually ceramic particles are added to aluminium or $\mathrm{Al}$ alloys, like $\mathrm{ZrO}_{2}, \mathrm{SiC}$, or $\mathrm{TiB}_{2}$. Adding ceramic particles to $\mathrm{Al}$ results in increasing of mechanical properties (strength, hardness) of the material. Therefore, these composites attract a lot of interest due to their possible applications as lightweight constructional parts in automotive and aerospace industry.

Recently a new group of MMCs has been reported in literature, namely crystalline-amorphous composites. Such composites consist of two metallic phases, however one of them is crystalline, while the second one - amorphous. Therefore, the term "composite" is related to crystal structure of the components applied (crystalline and amorphous), not to type of material. Dutkiewicz et al. [1] reported fabrication of the composite with $\mathrm{Zr}$ based amorphous matrix reinforced with $20-50 \%$ volume fraction of crystalline Ag particles, applying hot pressing of powders under the pressure of $600 \mathrm{MPa}$ at the temperature lower than crystallization temperature of amorphous matrix. Dudina et al. [2] fabricated composite with Mg-based AZ91 crystalline matrix reinforced with powders obtained by ball milling of Vitraloy 6 metallic glass, applying the pressure of $50 \mathrm{MPa}$, temperature of $440{ }^{\circ} \mathrm{C}$ and induction sintering technique. The same compaction technique has been applied by Dudina et al. [3] for obtaining the composite with Al 520 commercial alloy as a matrix and $\mathrm{Cu}$-based metallic amorphous parti-

*corresponding author; e-mail: doleszak@inmat.pw.edu.pl cles, fabricated by ball milling of metallic glass ribbon, as reinforcement. Crystalline-amorphous composites can be also manufactured applying various in situ methods. Kozieł et al. [4] obtained amorphous Fe-rich and crystalline $\mathrm{Cu}$-rich phases directly during solidification of the FeCuNiAlSiB alloy, applying the effect of liquid phase separation due to positive heat of mixing between two major elements, namely $\mathrm{Fe}$ and $\mathrm{Cu}$. On the other hand, Deibler and Findley [5] reported fabrication of amorphous-crystalline composite in the MgCuZnY system, applying cooling of the liquid alloy at a rate slightly less than the critical cooling rate, followed by annealing of the alloy. This fabrication procedure resulted in amorphous matrix and crystalline $\mathrm{Mg}_{2} \mathrm{Cu}$ and $\mathrm{Mg}_{3} \mathrm{Y}_{2} \mathrm{Zn}_{3}$ phases. The authors of all cited above papers claim that addition of amorphous component to the crystalline alloy matrix results in improvement of their mechanical properties (strength, hardness, wear resistance). However, in the literature there are no reports on the composites in which both phases (crystalline and amorphous) are Al-based.

In this work fabrication of crystalline-amorphous composites is proposed, applying Al-based metallic alloys both as matrix and reinforcement. As a crystalline matrix commercial powders of $\mathrm{Al}$ based alloy have been used, while amorphous powders have been obtained by traditional mechanical alloying. For powder compaction non-conventional high pressure high temperature (HPHT) method has been employed.

\section{Experimental details}

AA6061 commercial atomized powders have been used as crystalline matrix of the composites, while amorphous $\mathrm{Al}_{60} \mathrm{Nb}_{40}$ powders have been fabricated by mechanical alloying method starting from the mixture of powders of pure crystalline elements. The milling process was performed in the stainless-steel vial of a Spex8000D shaker ball mill equipped with hardened steel balls. The ballto-powder weight ratio was 10:1. Next, three powders mixtures containing 10, 20, and $30 \mathrm{vol} . \%$ of amorphous 
component have been prepared by dry mixing for $24 \mathrm{~h}$. For powder compaction HPHT method has been employed. The compaction procedure has been performed applying the pressure of $7.7 \mathrm{GPa}$ at 600 and $1000^{\circ} \mathrm{C}$ for 3 min. The phase composition of the composites has been checked by X-ray diffraction (XRD) using Rigaku MiniFlex II diffractometer with $\mathrm{Cu} K_{\alpha}$ radiation. The structure of the sintered compacts has been studied by scanning electron microscopy (Hitachi S-3500N). Hardness measurements have been performed in order to evaluate mechanical properties of the composites.

\section{Results and discussions}

XRD patterns of composites containing 30 vol. $\%$ of amorphous $\mathrm{Al}_{60} \mathrm{Nb}_{40}$ phase processed by HPHT method at 600 and $1000{ }^{\circ} \mathrm{C}$ are shown in Fig. 1. For both patterns diffraction lines belonging to $\alpha$ - $\mathrm{Al}$ solid solution and diffused halo typical for amorphous phase are visible. The crystallization temperature of amorphous phase determined by calorimetric studies at heating rate of $40^{\circ} \mathrm{C} / \mathrm{min}$ was $908^{\circ} \mathrm{C}$. Therefore, it is worth to underline that the applied high pressure allowed to preserve the amorphous phase in the composite structure even at compaction temperature of $1000^{\circ} \mathrm{C}$, i.e. above the crystallization temperature. Other factors influencing this result are: short compaction time (3 min) and high rate of heating from room temperature to applied sintering temperature, moving crystallization processes of amorphous component to even higher temperature range. It is known that crystallization temperature of amorphous alloy determined by thermal measurements depends on heating rate.

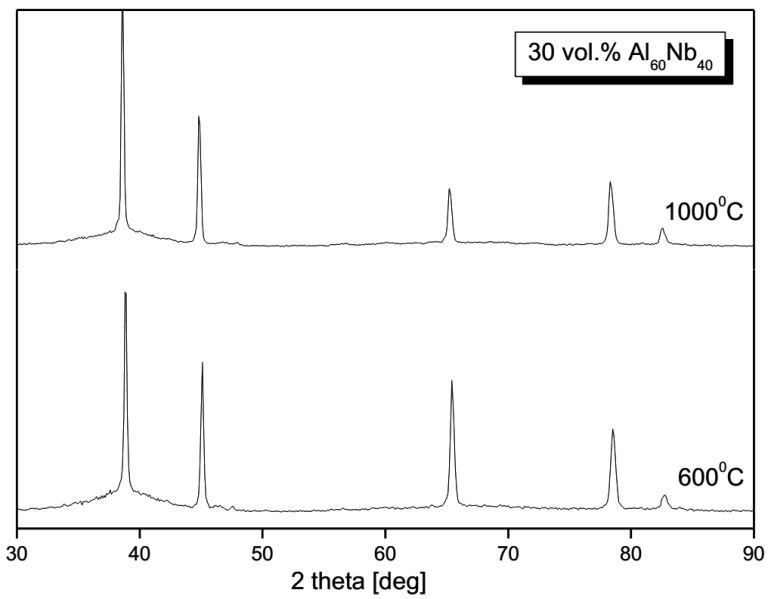

Fig. 1. XRD patterns of composites containing 30 vol.\% of amorphous $\mathrm{Al}_{60} \mathrm{Nb}_{40}$ phase, processed by HPHT method at 600 and $1000^{\circ} \mathrm{C}$.

SEM micrographs showing the results of microstructure studies of the sinters are presented in Figs. 2-5. At all micrographs AA6061 crystalline matrix is visible as dark area, while amorphous AlNb phase is visible in light colour. For all presented samples, independently of compaction temperature and volume fraction of amorphous component, the quality of the compacts is very good, there are no cracks or pores. The relative density of the sinters was above $98 \%$. Next, a strong tendency of agglomeration of amorphous alloy particles is visible. The average particle size of amorphous $\mathrm{Al}_{60} \mathrm{Nb}_{40}$ powder after mechanical alloying was $10 \mu \mathrm{m}$, however, the range of particle sizes was from 1 to $100 \mu \mathrm{m}$, and before compaction the powders were not sieved. Finally, the characteristic microstructure of the sinters is observed - small amorphous powders surround bigger particles of AA6061 alloy. Therefore, the microstructure of the composites is not fully homogeneous.

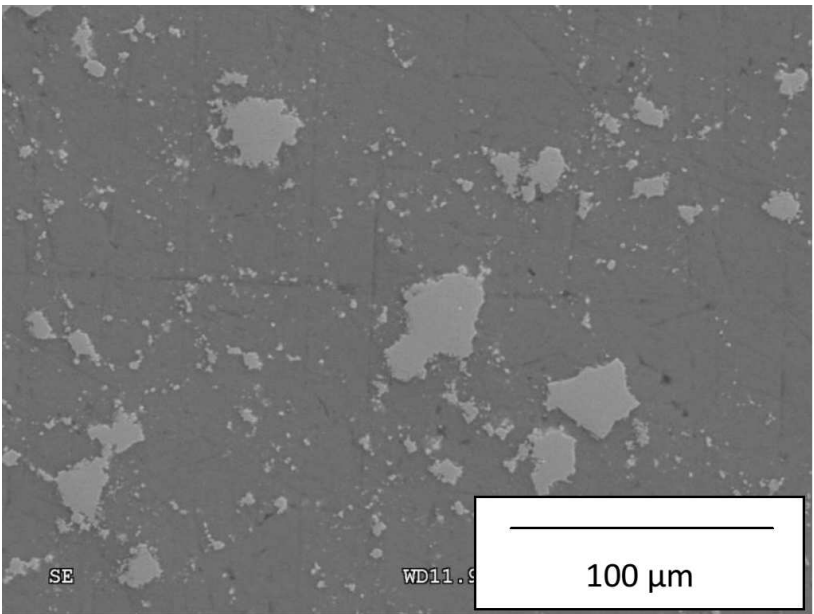

Fig. 2. SEM micrograph of composite containing $10 \mathrm{vol} . \%$ of amorphous component sintered at $600{ }^{\circ} \mathrm{C}$.

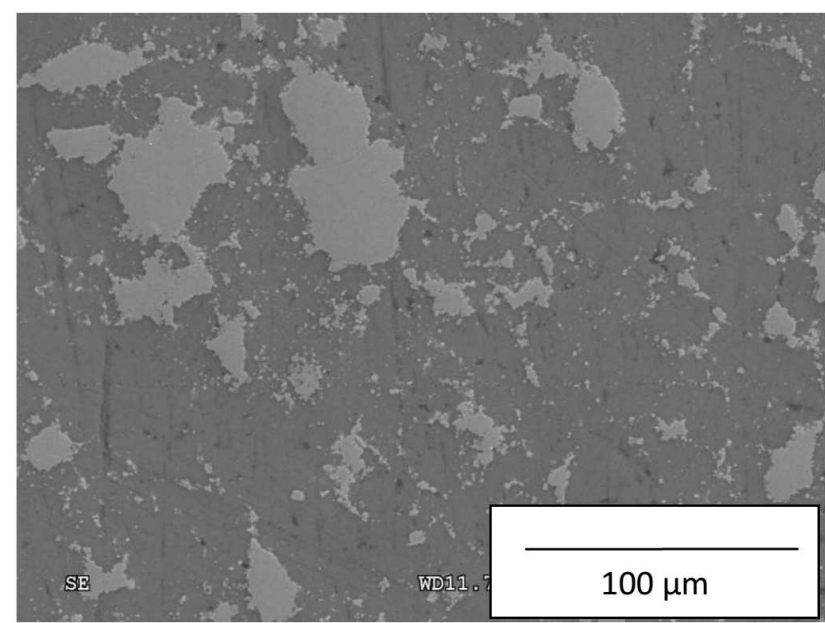

Fig. 3. SEM micrograph of composite containing 20 vol.\% of amorphous component sintered at $600{ }^{\circ} \mathrm{C}$.

Hardness measurements show that addition of amorphous component to crystalline Al6061 phase results in improvement of mechanical properties of the composites. The values of hardness increase from $75 \mathrm{HV}$ for reference sample (no amorphous component) compacted at $600^{\circ} \mathrm{C}$, through $88 \mathrm{HV}$ for 10 vol.\% of amorphous phase, $106 \mathrm{HV}$ for $20 \mathrm{vol} . \%$ and finally up to $120 \mathrm{HV}$ for the sample containing $30 \mathrm{vol} . \%$ of $\mathrm{Al}_{60} \mathrm{Nb}_{40}$. The influence of compaction temperature on hardness was not observed. 


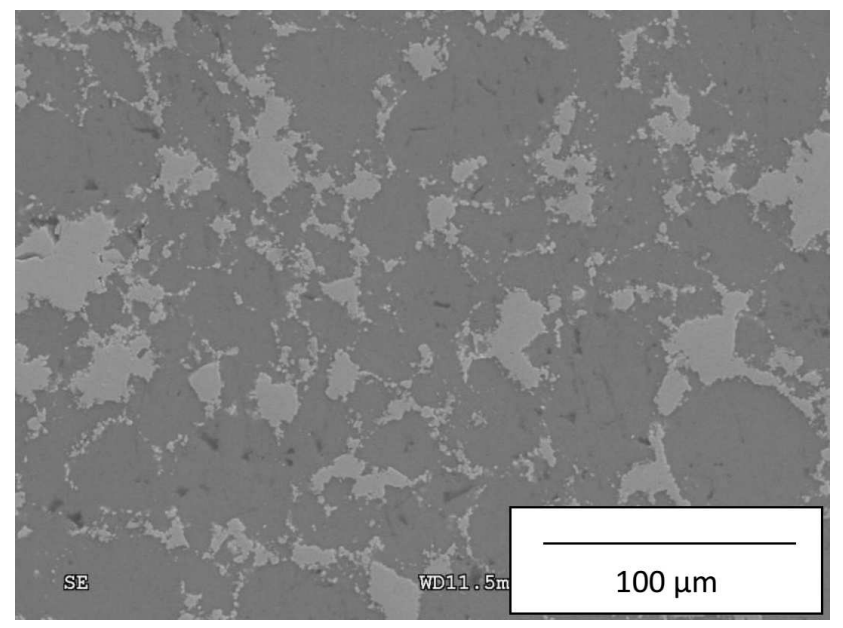

Fig. 4. SEM micrograph of composite containing 30 vol.\% of amorphous component sintered at $600{ }^{\circ} \mathrm{C}$.

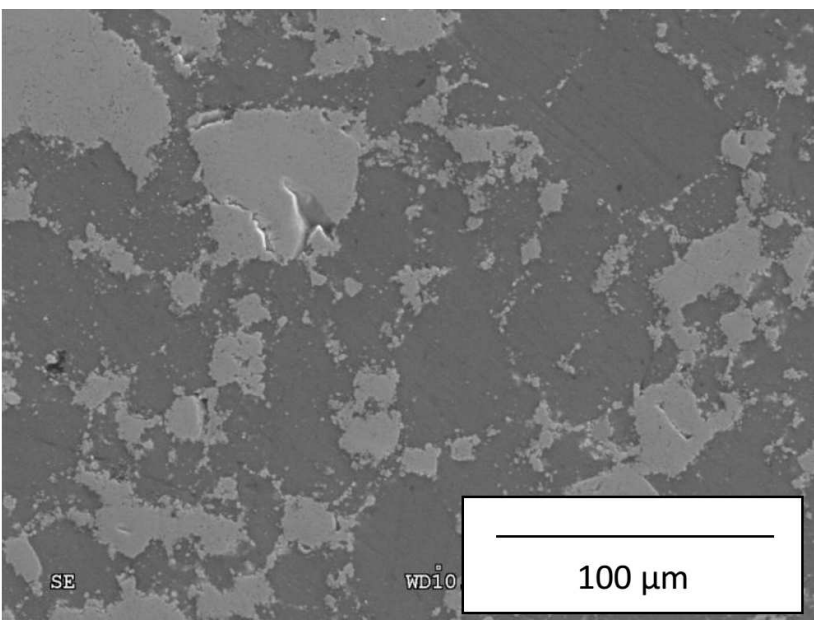

Fig. 5. SEM micrograph of composite containing 30 vol.\% of amorphous component sintered at $1000{ }^{\circ} \mathrm{C}$.

\section{Conclusions}

It was shown that it is possible, after careful choosing of compaction parameters, to obtain bulk crystallineamorphous Al-based composites. High pressure and short compaction time applied allowed preservation of amorphous phase, without its crystallization. The presence of amorphous component in composites structure results in improving mechanical properties of the material, in comparison with pure crystalline AA6061 alloy powders sintered at the same conditions. Significant increase of hardness was observed, from 75 to $120 \mathrm{HV}$.

\section{Acknowledgments}

Financial support of National Science Centre under the contract No 2011/01/B/ST8/07068 is highly appreciated.

\section{References}

[1] J. Dutkiewicz, L. Litynska-Dobrzyńska, W. Maziarz, T. Czeppe, A. Kukuła, L. Rogal, J. Alloys Comp. 509, 161 (2011).

[2] D.V. Dudina, K. Georgarakis, Y. Li, M. Aljerf, A. LeMoulec, A.R. Yavari, A. Inoue, Compos. Sci. Technol. 69, 2734 (2009).

[3] D.V. Dudina, K. Georgarakis, M. Aljerf, Y. Li, M. Braccini, A.R. Yavari, A. Inoue, Compos. Part A 41, 1551 (2010).

[4] T. Kozieł, A. Zielinska-Lipiec, J. Latuch, S. Kac, J. Alloys Comp. 509, 4891 (2011).

[5] L.A. Deibler, K.O. Findley, J. Alloys Comp. 463, 173 (2008). 